\title{
Late Feeding Tube Dependency in Head and Neck Cancer Patients Treated with Definitive Radiation Therapy and Concurrent Systemic Therapy
}

Cole Friedes ${ }^{1}$, Jessica Klingensmith ${ }^{2}$, Nana Nimo ${ }^{3}$, Jessica Gregor ${ }^{4}$, Ryan Burri ${ }^{5}$

1. Medicine, University of Central Florida College of Medicine, Orlando, USA 2. Family Medicine, St. Petersburg General Hospital, St. Petersburg, USA 3. Medicine, University of South Florida Morsani College of Medicine, Tampa, USA 4. Speech Pathology, Cleveland Clinic Florida, Weston, USA 5. Radiation Oncology, C.W. Bill Young Veterans Affairs Medical Center, Bay Pines, USA

Corresponding author: Ryan Burri, ryan.burri@va.gov

\section{Abstract}

\section{Objective}

The study aimed to evaluate the impact of late swallowing dysfunction leading to percutaneous endoscopic gastrostomy (PEG) tube dependence on the overall survival (OS) in a cohort of locally advanced head and neck cancer patients treated and cured with definitive radiotherapy (RT) and concurrent systemic therapy (CST).

\section{Materials and methods}

A total of 62 patients with locally advanced head and neck cancer were included in the analysis based on the following selection criteria: stage III, IVA, or IVB disease, treated with definitive RT and CST, no major head and neck surgery, no evidence of local or distant recurrent disease, and at least one post-RT modified barium swallow study. Patients were classified as PEG dependent or PEG independent at the time of the last followup. Estimates of OS were calculated using the Kaplan-Meier method. Univariate and multivariate analyses were performed to evaluate the impact of various clinical factors on OS.

\section{Results}

The median follow-up was 48 months (range: 7.6-235 months). The five-year OS was $64.3 \%$ in the PEGdependent group and $86.1 \%$ in the PEG-independent group $(\mathrm{p}=0.022)$. Age over 70 at diagnosis was also associated with poorer OS ( $\mathrm{p}=0.044)$. On univariate analysis, $\mathrm{PEG}$ dependency maintained a significantly worse OS (hazard ratio [HR]: 2.59; 95\% confidence interval [CI]: 1.11-5.99, $\mathrm{p}=0.028$ ). On multivariate analysis, PEG dependency (HR: 4.25 ; $95 \%$ CI: 1.33-13.62; $\mathrm{p}=0.015$ ), advanced $\mathrm{N}$ stage (HR: $4.74 ; 95 \% \mathrm{CI}$ : 1.17-19.26, $\mathrm{p}=0.035$ ), and older age at diagnosis (HR: 4.37 ; $95 \%$ CI: $1.21-15.84 ; \mathrm{p}=0.025$ ) were significantly associated with worse OS.

Received 03/02/2020

Review began 03/30/2020 Review ended 04/06/2020 Published 04/15/2020

() Copyright 2020

Friedes et al. This is an open access article distributed under the terms of the Creative Commons Attribution License CC-BY 4.0., which permits unrestricted use, distribution, and reproduction in any medium, provided the original author and source are credited.

\section{Conclusions}

Late PEG dependency is associated with poor OS in head and neck cancer patients cured with definitive RT and CST. Interventions designed to help head and neck cancer patients maintain swallowing function may result in improved outcomes.

Categories: Otolaryngology, Radiation Oncology, Oncology

Keywords: peg tube, swallowing, dysphagia, chemoradiation, peg dependency, veterans affairs, head and neck cancer

\section{Introduction}

Head and neck cancer is common among the United States Veteran population and is increasingly being managed with organ preservation strategies [1]. Radiotherapy (RT) with or without concurrent systemic therapy (CST) can result in a long-term cure in patients with a variety of primary sites and stages, but late toxicity such as dysphagia and swallowing dysfunction can be debilitating and permanent and lead to dependence on enteral feeding [2-6]. Late percutaneous endoscopic gastrostomy (PEG) tube dependence has been associated with a variety of clinical and tumor factors, but the association between late swallowing dysfunction and overall survival (OS) has not been explored [7-9]. The hypothesis of this retrospective study is that late swallowing dysfunction necessitating PEG support is associated with worse OS in patients with locally advanced head and neck cancer patients cured with definitive RT and CST.

\section{Materials And Methods}

\section{Patient and treatment characteristics}




\section{Cureus}

The study population included veteran patients referred for a formal swallowing evaluation between 2008 and 2017 to the Speech Pathology Clinic at the Bay Pines VA Healthcare System, C.W. Bill Young Veterans Affairs (VA) Medical Center, after completion of definitive RT and CST for locally advanced head and neck cancer. Informed consent was waived for this Institutional Review Board approved retrospective review of patient medical records.

Patients were included for analysis if they met the following criteria: biopsy-proven squamous cell carcinoma of the head and neck; American Joint Committee on Cancer (AJCC) 7th Edition stage III, IVA, or IVB disease; minimum follow-up of 90 days after completing RT; at least one post-RT modified barium swallow study; no evidence of disease at the time of the last follow-up; and treated with definitive RT and CST. Patients were excluded from analysis if they had undergone major head and neck surgery including definitive surgical resection or neck dissection, had evidence of local, regional, or distant recurrence of head and neck cancer, or had non-squamous cell carcinoma histology.

CPRS records were reviewed to determine disease status at the last follow-up, PEG dependency, overall length of follow-up, and survival status. Patients were assigned either PEG-dependent or PEG-independent status at the time of the last follow-up.

\section{Statistical analysis}

Statistical analyses were performed using Statistical Product and Service Solutions (SPSS) Version 24.0 (IBM Corp., Chicago, Illinois, USA) to assess the relationship between clinical, tumor, and treatment characteristics, and PEG dependence and survival. Estimates of OS were calculated using the Kaplan-Meier method, and differences between groups were estimated with the log-rank test. OS was defined as years from the time of diagnosis to death or the last follow-up. Univariate and multivariate Cox-proportional hazards model was used to evaluate the impact of various clinical factors on OS. The chi-square test was used to assess any differences between PEG-dependent and PEG-independent groups at baseline. Statistical significance was defined as $\mathrm{p}<0.05$.

\section{Results}

\section{Patient cohort}

Overall, 62 patients were included in the final study population. Distribution of patient demographics, tumor primary site, and staging is available in Table 1 .

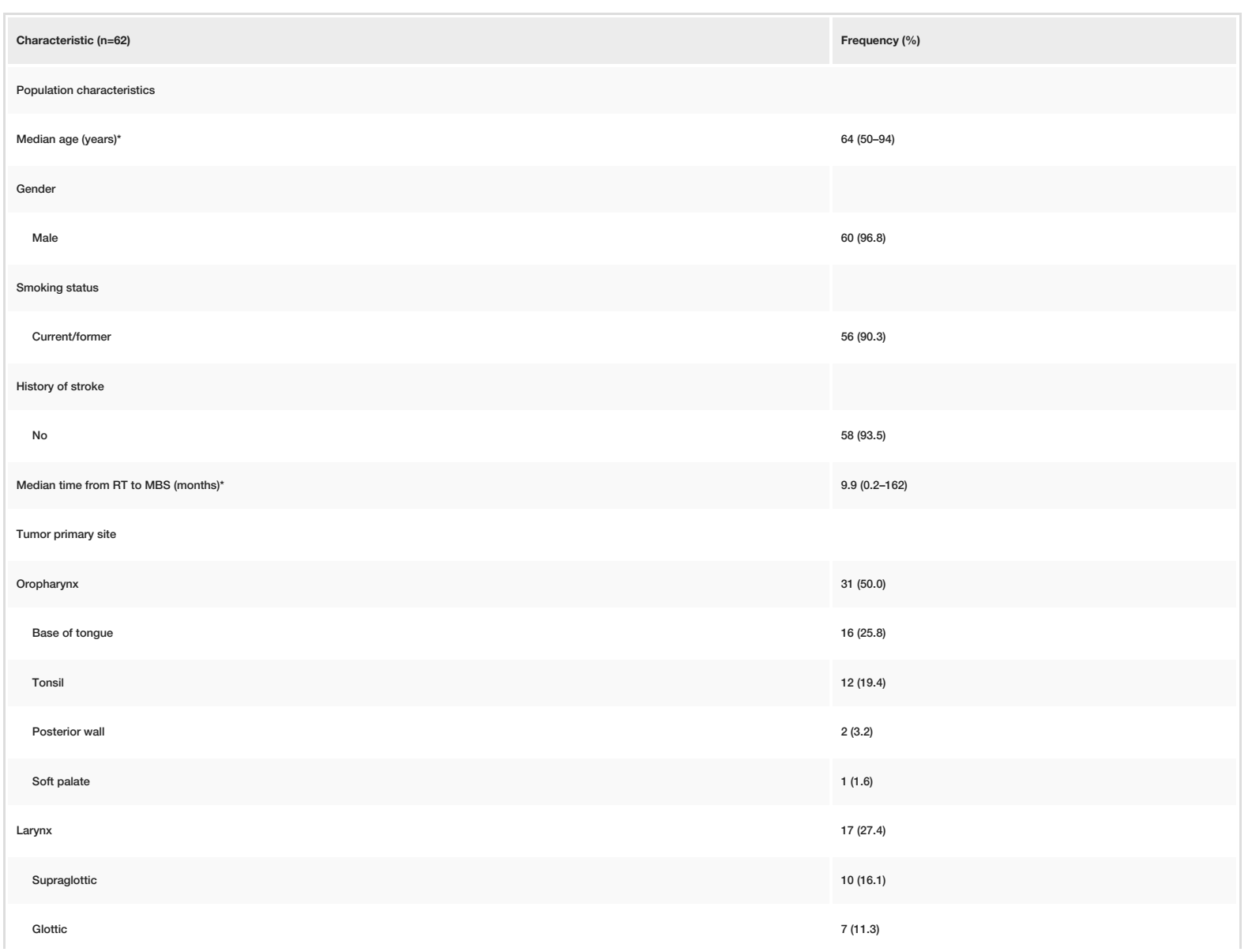


Cureus

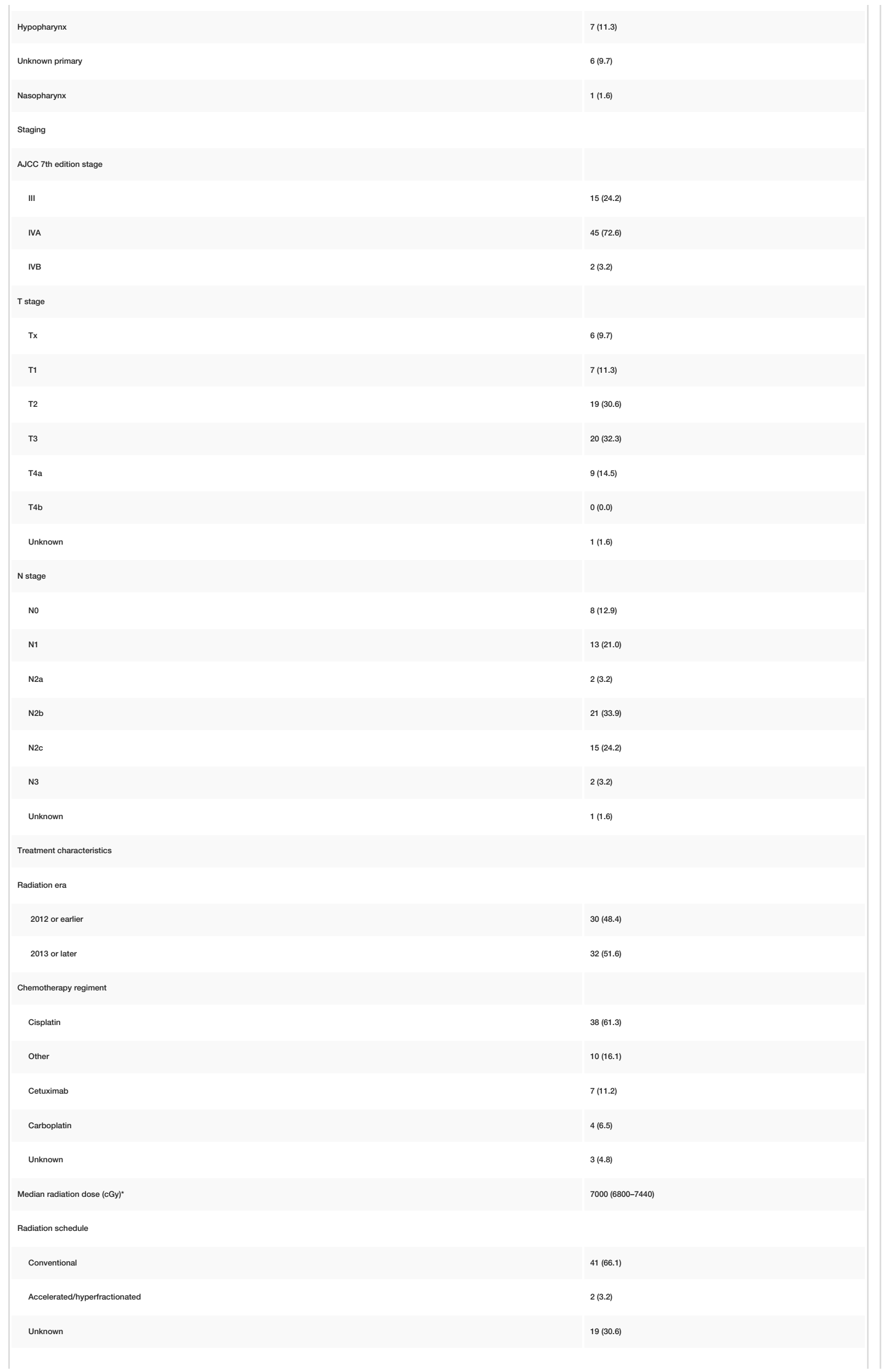

2020 Friedes et al. Cureus 12(4): e7683. DOI 10.7759/cureus.7683

3 of 11 


\section{Cureus}

Radiation modality

IMRT

3D conformal

Received hyperbaric oxygen

Yes

Prophylactic PEG

\section{TABLE 1: Patient characteristics, tumor primary site, and staging}

*Continuous variables are displayed as median (range)

RT, radiotherapy; MBS, modified barium swallow; AJCC, American Joint Committee on Cancer; IMRT, intensity-modulated radiotherapy; 3D, threedimensional; PEG, percutaneous endoscopic gastrostomy

The median patient age at the time of treatment was 64 years (range: $50-94$ years), with $96.8 \%$ of the cohort being males. Most patients were stage IVA at diagnosis $(72.6 \%, n=45)$, had oropharyngeal tumors $(50.0 \%$, $\mathrm{n}=31)$, and were treated with platinum-based CST (77.4\%, $\mathrm{n}=48)$. At the time of analysis, 46 (74.2\%) patients were considered PEG dependent and 16 (25.8\%) were determined to be PEG independent. Patient, tumor, and treatment characteristics were not significantly different between the PEG- dependent and PEGindependent groups (Table 2).

\begin{tabular}{|c|c|c|c|}
\hline Characteristic & PEG dependent $(n=16)$ & PEG independent ( $n=46)$ & $\mathrm{p}$-Value \\
\hline Stage & & & 0.555 \\
\hline III & 3 & 12 & \\
\hline IVA or IVB & 13 & 34 & \\
\hline T stage & & & 0.143 \\
\hline $\mathrm{T} 3$ or $\mathrm{T} 4$ & 10 & 19 & \\
\hline $\mathrm{T} 1$ or $\mathrm{T} 2$ & 6 & 27 & \\
\hline N stage & & & 0.367 \\
\hline N2c or N3 & 3 & 14 & \\
\hline N2b or lower & 13 & 32 & \\
\hline Radiation era & & & 0.881 \\
\hline 2012 or earlier & 8 & 22 & \\
\hline 2013 or later & 8 & 24 & \\
\hline Age at treatment & & & 0.101 \\
\hline 71 years or older & 5 & 6 & \\
\hline 70 years or under & 11 & 40 & \\
\hline Type of systemic therapy & & & 0.722 \\
\hline Cisplatin & 10 & 31 & \\
\hline Non-cisplatin & 6 & 15 & \\
\hline Hyperbaric oxygen & & & 0.068 \\
\hline Received HBO & 3 & 2 & \\
\hline Did not receive HBO & 13 & 44 & \\
\hline
\end{tabular}




\section{Cureus}

Prophylactic PEG

Yes

No

Unknown

Radiation modality

3D conformal

IMRT

Unknown

Tumor primary site

Larynx/hypopharynx

Other

Tobacco use

Yes/former

No
13
0.477

19

27

0.590

TABLE 2: Distribution of patient, tumor, and treatment characteristics in PEG-dependent and PEG-independent patients

PEG, percutaneous endoscopic gastrostomy; HBO, hyperbaric oxygen; 3D, three-dimensional; IMRT, intensity-modulated radiotherapy

\section{Factors influencing overall survival}

The following clinical information was collected and analyzed by univariate analysis for association with OS: PEG dependence, overall stage, T stage, N stage, radiation era, age at treatment, type of CST, use of hyperbaric oxygen, prophylactic PEG use, tumor primary site, and tobacco use (Table 3). 


\section{Cureus}

\begin{tabular}{|c|c|c|c|}
\hline Factor & Hazard ratio $(95 \% \mathrm{Cl})$ & Five-year OS (\%) & $\mathrm{p}$-value \\
\hline \multicolumn{4}{|l|}{ PEG dependence } \\
\hline PEG dependent & $2.59(1.11-5.99)$ & 64.3 & 0.028 \\
\hline PEG independent (reference) & & 86.1 & \\
\hline \multicolumn{4}{|l|}{ Stage } \\
\hline III & $1.46(0.25-1.91)$ & 75.8 & 0.468 \\
\hline IVA or IVB (reference) & & 83.0 & \\
\hline \multicolumn{4}{|l|}{ T stage } \\
\hline T3 or T4 & $1.05(0.40-2.23)$ & 88.1 & 0.904 \\
\hline T1 or T2 (reference) & & 74.0 & \\
\hline \multicolumn{4}{|l|}{ N stage } \\
\hline N2c or N3 & $0.65(0.62-3.82)$ & 73.7 & 0.353 \\
\hline N2b or lower (reference) & & 83.9 & \\
\hline \multicolumn{4}{|l|}{ Radiation era } \\
\hline 2012 or earlier & $2.70(0.09-1.53)$ & 90.0 (four-year oS) & 0.155 \\
\hline 2013 or later (reference) & & 80.2 (four-year oS) & \\
\hline \multicolumn{4}{|l|}{ Age at treatment } \\
\hline 71 years or older & $2.57(0.99-6.65)$ & 72.7 & 0.052 \\
\hline 70 years or under (reference) & & 82.9 & \\
\hline \multicolumn{4}{|l|}{ Type of systemic therapy } \\
\hline Cisplatin & $0.87(0.47-2.81)$ & 82.7 & 0.752 \\
\hline Non-cisplatin (reference) & & 75.2 & \\
\hline \multicolumn{4}{|l|}{ Hyperbaric oxygen } \\
\hline Received HBO & 0.68 (0.49-4.45) & 60.0 & 0.486 \\
\hline Did not receive HBO (reference)) & & 83.4 & \\
\hline \multicolumn{4}{|l|}{ Prophylactic PEG } \\
\hline Yes & $0.52(0.63-5.85)$ & 79.4 & 0.248 \\
\hline No (reference) & & 87.5 & \\
\hline \multicolumn{4}{|l|}{ Primary site } \\
\hline Larynx/hypopharynx & $1.16(0.35-2.09)$ & 75.8 & 0.740 \\
\hline Other (reference) & & 83.9 & \\
\hline \multicolumn{4}{|l|}{ Tobacco use } \\
\hline Yes/former & $0.78(0.30-5.62)$ & 80.8 & 0.734 \\
\hline No (referen & & 80.0 & \\
\hline
\end{tabular}

TABLE 3: Univariate analysis of patient and treatment characteristics associated with OS

$\mathrm{CI}$, confidence interval; OS, overall survival; PEG, percutaneous endoscopic gastrostomy; $\mathrm{HBO}$, hyperbaric oxygen 


\section{Cureus}

radiation modality and dose was not included in the univariate and multivariate analyses.

On univariate analysis, PEG-dependent patients (hazard ratio [HR]: 2.59; 95\% confidence interval [CI]: 1.115.99; $\mathrm{p}=0.028$ ) and patients aged 71 years or older at treatment (HR: 2.57 ; 95\% CI: 0.99-6.65; $\mathrm{p}=0.052$ ) had worse OS outcomes. No other factors were associated with OS on univariate analysis. On multivariate analysis, the following were recognized to have worse OS: PEG dependency (HR: 4.25; 95\% CI: 1.33-13.62; $\mathrm{p}=0.015$ ), advanced N stage (HR: $4.74 ; 95 \% \mathrm{CI}: 1.17-19.26$; $\mathrm{p}=0.032$ ), and older age at treatment (HR: 4.37; 95\% CI: 1.21-15.84; $\mathrm{p}=0.014$ ) (Table 4).

\begin{tabular}{|c|c|c|}
\hline Factor & Hazard ratio $(95 \% \mathrm{Cl})$ & $\mathrm{p}$-Value \\
\hline PEG dependence & $4.25(1.33-13.62)$ & 0.015 \\
\hline Lower overall stage & $1.06(0.21-5.45)$ & 0.945 \\
\hline Higher T stage & $1.16(0.44-3.04)$ & 0.763 \\
\hline Higher N stage & $4.74(1.17-19.26)$ & 0.030 \\
\hline Earlier radiation era & $0.36(0.07-1.84)$ & 0.220 \\
\hline Older age at treatment & $4.37(1.21-15.84)$ & 0.025 \\
\hline Cisplatin therapy & $1.20(0.44-3.29)$ & 0.719 \\
\hline $\mathrm{HBO}$ use & $1.18(0.31-4.48)$ & 0.808 \\
\hline Prophylactic PEG & $3.09(0.75-12.78)$ & 0.119 \\
\hline Primary tumor site & $1.10(0.29-4.16)$ & 0.884 \\
\hline Tobacco use & $0.53(0.07-3.93)$ & 0.530 \\
\hline
\end{tabular}

TABLE 4: Multivariable Analysis of patient and treatment characteristics associated with survival

$\mathrm{Cl}$, confidence interval; PEG, percutaneous endoscopic gastrostomy; $\mathrm{HBO}$, hyperbaric oxygen

The median follow-up after the completion of definitive RT and CST was 48 months (range: 7.6-235 months). There was an observed worsening in OS for PEG-dependent patients (median of 6.54 years [95\% CI: 3.62 - NA] with PEG dependence vs. median of 9.39 years [95\% CI: 7.90 - NA] with PEG independence). The five-year OS was 64.3\% in the PEG-dependent group and 86.1\% in the PEG-independent group ( $\mathrm{p}=0.022)$ (Figure 1). Older age at treatment was also associated with poorer OS ( $\mathrm{p}=0.044$, not shown). 


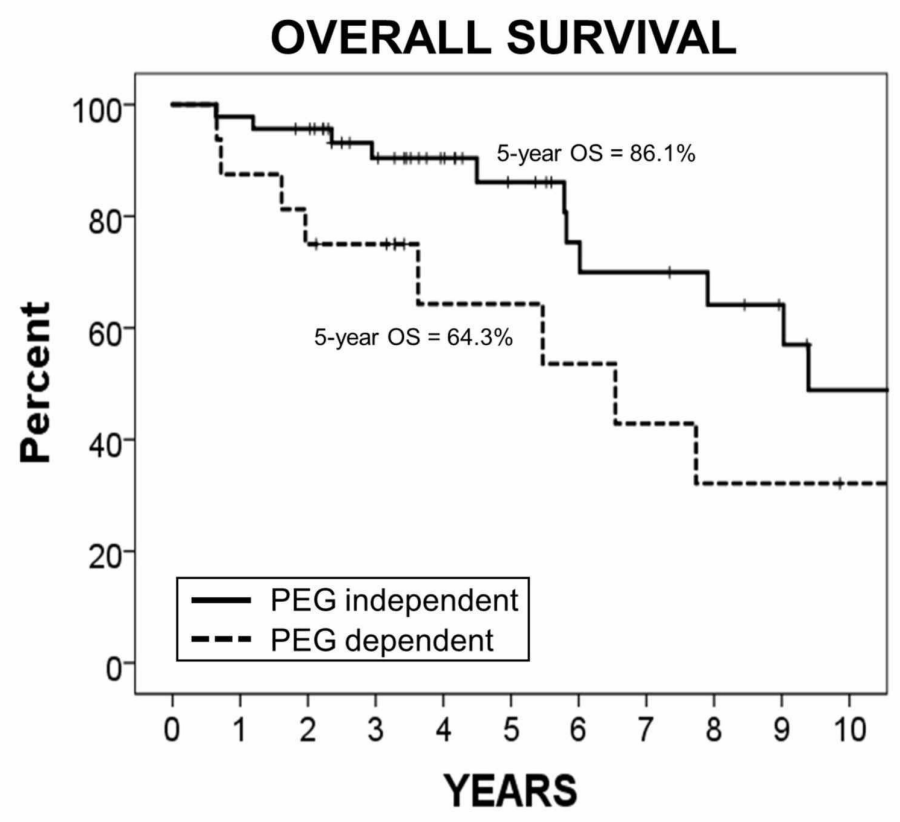

\begin{tabular}{|llllllllllll|}
\hline No. at Risk & & & & & & & & & & & \\
PEG independent & 46 & 45 & 43 & 33 & 25 & 19 & 14 & 13 & 11 & 9 & 6 \\
PEG dependent & 16 & 14 & 12 & 11 & 6 & 6 & 5 & 4 & 3 & 3 & 2 \\
\hline
\end{tabular}

\author{
FIGURE 1: The Kaplan-Meier survival curve showing OS for PEG- \\ dependent (dashed line) and PEG-independent (solid line) patients, \\ $\mathrm{p}=0.022$ (log-rank test) \\ OS, overall survival; PEG, percutaneous endoscopic gastrostomy
}

\title{
Discussion
}

In a cohort of patients with non-resected stage III or IVA/B head and neck squamous cell carcinoma definitively cured with RT and CST in the C.W. Bill Young VA Medical Center, we found that PEG dependency was significantly associated with worse OS compared with PEG-independence. Therefore, long-term RT and CST toxicities leading to late feeding tube dependence may have substantial survival implications, and the provider decision for PEG placement should be weighed heavily. Similarly, in accordance with the NCCN (National Comprehensive Cancer Network) guidelines and other literature, prophylactic PEG tubes and enteral feeding should only be employed when unequivocally necessitated $[10,11]$. The risks of potential PEG tube dependence must be weighed against the nutritional benefits. By the best of our knowledge, this is the first report describing survival outcomes in a PEG-dependent cohort in comparison with their PEGindependent counterparts.

It is well known that organ-preserving strategies used to cure locally advanced head and neck carcinoma may induce significant acute and long-term side effects. Acute toxicities such as skin toxicity or mucositis often temporarily disrupt swallowing function during treatment but are often transient in nature. In contrast, late effects including neuropathy and fibrosis of oropharyngeal musculature may result in permanently disabling dysphagia, necessitating enteral support to reduce the risk of life-threatening pneumonia and support nutritional habits [12-14]. One smaller study found that as a result of late toxicity dysphagia, $66 \%$ of the cohort was gastrostomy-dependent [15]. Known predictors of PEG tube placement include patient advanced age, primary tumor site, smoking status, higher $\mathrm{T}$ and $\mathrm{N}$ stages, body mass index of less than 25, accelerated irradiation fractionation, and use of high-dose chemotherapy [7,9].

While feeding tube dependency is relatively common, few studies have explored the relationship between enteral support and survival $[4,5,16,17]$. At the time of the last follow-up, 16 (26\%) patients of our cohort were found to be feeding tube dependent. In the GORTEC 99-02 trial comparing fractionation schedules for 
locally advanced head and neck carcinoma, rates of feeding tube placement varied, with $60 \%$ in the conventionally fractionated group, 64\% in the hyperfractionated, and $70 \%$ in the very accelerated RT patients. At the five-year follow-up, $13 \%$ of conventionally fractionated patients were feeding tube dependent versus $25 \%$ of the very accelerated RT group $(p=0.027)$ [4]. Pooled analyses have also demonstrated a feeding tube dependency rate of $10.3 \%$ in a locally advanced cohort [5]. A small retrospective study evaluated the timing of PEG placement and OS and showed that prophylactic PEG use had worse outcomes (HR: 11.62; 95\% CI: 1.77-76.47; p=0.011) [17]. However, this study did not evaluate long-term PEG dependency and may thus explain our study results that prophylactic PEG use did not result in worse OS, rather long-term PEG dependency appears to be a key factor in driving survival.

Reducing post-chemoradiation toxicity may improve OS due to decreased PEG tube dependence. The mean dose to swallowing organs significantly predicts long-term dysphagia; ergo, it is possible that intensitymodulated RT (IMRT) may lead to less dysphagia as the technique can spare the pharyngeal constrictor muscles and supraglottic larynx [18,19]. Although not yet clinically validated, the introduction of functional swallowing units (FSUs), defined by hyolaryngeal elevation, tongue base retraction, and tongue motion, is certainly promising. Using these contouring guidelines to mark the delineation of FSUs may reduce toxicity, leading to better outcomes [20,21]. A new randomized control trial is planned to more definitively explore the role of IMRT in reducing dysphagia [22]. Regarding our study, more than half of our cohort received IMRT-based therapy. However, due to unavailable data for $35.5 \%$ of patients, radiation modality was not included in our survival analysis. Of the 36 IMRT patients, only 7 (19.4\%) were PEG dependent at the last follow-up. Future research may show that patients receiving IMRT have better outcomes due to less PEG dependency.

Similarly, toxicity mitigation through non-treatment altering programs offers promise in the reduction of late dysphagia. Prophylactic swallowing programs have frequently been investigated as an attempt to reduce post-radiation fibrosis and improve dysphagia-related outcomes [23-26]. Carnaby-Mann et al. demonstrated that twice daily swallowing musculature exercises resulted in significantly less dysphagia compared with usual care and sham exercises, whereas van der Molen et al. showed that preventative exercises resulted in less feeding tube dependency compared with other institutional trials [23,25]. Overall, these studies concluded that swallowing programs have a beneficial reduction in acute swallowing issues. However, longterm outcomes and if these programs lead to a reduction in PEG dependence or OS are still unknown. On the other hand, additional retrospective studies have shown that prophylactic PEG tubes often lead to increased esophageal strictures and increased PEG dependence, and do not impact treatment times [10,24,27]. These previous studies suggest that avoidance of prophylactic PEG tubes may improve outcomes, which is reinforced by our findings that PEG dependence is associated with worse OS.

Recently, efforts to de-intensify treatment to reduce significant toxicity while delivering similar efficacy have been explored. A recent analysis of VA patients receiving definitive concurrent chemoradiation for stage III-IVB unresectable head and neck cancer showed that low-dose cisplatin compared with high-dose cisplatin resulted in no change in survival with simultaneous toxicity reduction [28]. Similarly, in an early de-intensification trial, Chera et al. showed that de-intensification of chemoradiotherapy (e.g., with 60 Gy of IMRT and ipsilateral RT for tonsil cancers) resulted in favorable outcomes [6]. In the evolving era of immunotherapy, we anticipate the incorporation of immunotherapy into the standard of care for locally advanced and advanced head and neck carcinomas. We eagerly anticipate the results of two clinical trials evaluating the role of pembrolizumab in locally advanced head and neck malignancies (NCT03040999) and in patients who are cisplatin-ineligible due to significant toxicity (NCT02609503).

We acknowledge that there are limitations of a small cohort-based, retrospective analysis. First, our study did not have the means to assess human papillomavirus (HPV) or p16 status. These factors offer a prognostic benefit to patients with squamous cancers of the head and neck and can significantly alter outcomes [29]. Specific staging for HPV positive oropharyngeal cancer has been adopted in the AJCC 8th edition staging guidelines; therefore, a more careful stratification of non-HPV or HPV-related cancers in patients with PEG dependence must be assessed. Due to the nature of our study, we are unaware of the indications for original PEG tube placement or for the nature of speech pathology referral. Protocols for PEG placement often vary at clinical institutions, and the uncertainty as to why each PEG tube was used offers confounding factors in our study. Also, our study does not include data regarding nasogastric tubes, which are sometimes used as an alternative to PEG tubes. Finally, we acknowledge that our survival outcomes are far superior to landmark and other similar trials. The five-year OS rates reported in these trials range from approximately 20 to $45 \%$, depending on the primary site $[28,30]$. The actuarial five-year OS for this patient cohort was higher $(84.1 \%$ for PEG-independent patients and 64.3\% for PEG-dependent patients) because only patients who had no evidence of disease at the time of the last follow-up were included in the analysis. The study was designed in this manner to decrease confounding on OS and further strengthen the relationship between late swallowing dysfunction, PEG dependency, and OS.

In the future, we hope to expand our analyses from our single institution. We aim to use the VA Corporate Data Warehouse (CDW) to achieve this goal. The CDW pools medical records from VA centers and other government databases across the nation to afford the opportunity for large-scale data mining and allow access to multicenter informatics. We anticipate that expanding our study cohort may offer more insight into the details that explain our findings. 


\section{Conclusions}

In conclusion, our data suggest that PEG dependence is significantly associated with worse OS, further supporting the fact that minimizing RT and CST side effects drastically improves patient care. Providers should carefully consider the use of enteral feeding and recognize the potential risks associated with late feeding tube dependency.

\section{Additional Information \\ Disclosures}

Human subjects: All authors have confirmed that this study did not involve human participants or tissue. Animal subjects: All authors have confirmed that this study did not involve animal subjects or tissue. Conflicts of interest: In compliance with the ICMJE uniform disclosure form, all authors declare the following: Payment/services info: All authors have declared that no financial support was received from any organization for the submitted work. Financial relationships: All authors have declared that they have no financial relationships at present or within the previous three years with any organizations that might have an interest in the submitted work. Other relationships: All authors have declared that there are no other relationships or activities that could appear to have influenced the submitted work.

\section{Acknowledgements}

This study is a result of work supported with resources and the use of facilities at the Bay Pines VA Healthcare System (BPVAHCS). The contents of this work do not represent the views of the U.S. Department of Veterans Affairs or the United States Government.

\section{References}

1. Parsons JT, Greene BD: Summary of major radiation fractionation and chemotherapy trials for organ preservation therapy in locally advanced head and neck squamous cell carcinoma. Pract Radiat Oncol. 2015, 5:343-349. 10.1016/j.prro.2015.03.005

2. Nguyen NP, Smith HJ, Sallah S: Evaluation and management of swallowing dysfunction following chemoradiation for head and neck cancer. Curr Opin Otolaryngol Head Neck Surg. 2007, 15:130-133. 10.1097/MOO.0b013e32801da0e8

3. Pignon JP, le Maitre A, Maillard E, Bourhis J: Meta-analysis of chemotherapy in head and neck cancer (MACH-NC): an update on 93 randomised trials and 17,346 patients. Radiother Oncol. 2009, 92:4-14. 10.1016/j.radonc.2009.04.014

4. Bourhis J, Sire C, Graff P, et al.: Concomitant chemoradiotherapy versus acceleration of radiotherapy with or without concomitant chemotherapy in locally advanced head and neck carcinoma (GORTEC 99-02): an open-label phase 3 randomised trial. Lancet Oncol. 2012, 13:145-153. 10.1016/S1470-2045(11)70346-1

5. Setton J, Lee NY, Riaz N, et al.: A multi-institution pooled analysis of gastrostomy tube dependence in patients with oropharyngeal cancer treated with definitive intensity-modulated radiotherapy. Cancer. 2015, 121:294-301. 10.1002/cncr.29022

6. Chera BS, Amdur RJ, Green R, et al.: Phase II trial of de-intensified chemoradiotherapy for human papillomavirus-associated oropharyngeal squamous cell carcinoma. J Clin Oncol. 2019, 37:2661-2669. 10.1200/jco.19.01007

7. Bhayani MK, Hutcheson KA, Barringer DA, et al.: Gastrostomy tube placement in patients with oropharyngeal carcinoma treated with radiotherapy or chemoradiotherapy: factors affecting placement and dependence. Head Neck-J Sci Spec. 2013, 35:1634-1640. 10.1002/hed.23200

8. Setton J, Lee NY, Riaz N, et al.: A multi-institution pooled analysis of gastrostomy tube dependence in patients with oropharyngeal cancer treated with definitive intensity-modulated radiotherapy. Cancer. 2015, 121:294-301. 10.1002/cncr.29022

9. Strom T, Trotti AM, Kish J, et al.: Risk factors for percutaneous endoscopic gastrostomy tube placement during chemoradiotherapy for oropharyngeal cancer. JAMA Otolaryngol Head Neck Surg. 2013, 139:12421246. 10.1001/jamaoto.2013.5193

10. Gutt R, Krasnow SH, Hesham H, Burmeister A, Manning J: Role of prophylactic PEG and risk factors for PEG dependency in head and neck cancer patients undergoing radiotherapy. J Clin Oncol. 2015, 33:17017-17017. 10.1200/jco.2015.33.15_suppl.e17017

11. NCCN guidelines with NCCN evidence blocks ${ }^{\mathrm{TM}}$ - very advanced head and neck cancer . (2020). Accessed: March 1, 2020: https://www.nccn.org/professionals/physician_gls/pdf/head-and-neck_blocks.pdf.

12. Langendijk JA, Doornaert P, Verdonck-de Leeuw IM, Leemans CR, Aaronson NK, Slotman BJ: Impact of late treatment-related toxicity on quality of life among patients with head and neck cancer treated with radiotherapy. J Clin Oncol. 2008, 26:3770-3776. 10.1200/JCO.2007.14.6647

13. Martin M, Lefaix J, Delanian S: TGF-beta1 and radiation fibrosis: a master switch and a specific therapeutic target?. Int J Radiat Oncol Biol Phys. 2000, 47:277-290. 10.1016/s0360-3016(00)00435-1

14. Eisbruch A, Lyden T, Bradford CR, et al.: Objective assessment of swallowing dysfunction and aspiration after radiation concurrent with chemotherapy for head-and-neck cancer. Int J Radiat Oncol Biol Phys. 2002, 53:23-28. 10.1016/S0360-3016(02)02712-8

15. Hutcheson KA, Lewin JS, Barringer DA, et al.: Late dysphagia after radiotherapy-based treatment of head and neck cancer. Cancer. 2012, 118:5793-5799. 10.1002/cncr.27631

16. Budach V, Stuschke M, Budach W, et al.: Hyperfractionated accelerated chemoradiation with concurrent fluorouracil-mitomycin is more effective than dose-escalated hyperfractionated accelerated radiation therapy alone in locally advanced head and neck cancer: Final results of the radiotherapy cooperative 
clinical trials group of the german cancer society 95-06 prospective randomized trial. J Clin Oncol. 2005, 23:1125-1135. 10.1200/TCO.2005.07.010

17. Baine MJ, Dorius T, Bennion N, Smith L, Zhen W, Ganti AK: Weight loss and percutaneous endoscopic gastrostomy tube placement during chemoradiotherapy for locally advanced cancer of the oropharynx do not negatively impact outcomes. Front Oncol. 2017, 7:299. 10.3389/fonc.2017.00299

18. Eisbruch A, Schwartz M, Rasch C, et al.: Dysphagia and aspiration after chemoradiotherapy for head-andneck cancer: Which anatomic structures are affected and can they be spared by IMRT?. Int J Radiat Oncol Biol Phys. 2004, 60:1425-1439. 10.1016/j.ijrobp.2004.05.050

19. Eisbruch A, Kim HM, Feng FY, et al.: Chemo-IMRT of oropharyngeal cancer aiming to reduce dysphagia: Swallowing organs late complication probabilities and dosimetric correlates. Int J Radiat Oncol Biol Phys. 2011, 81:93-99. 10.1016/j.ijrobp.2010.12.067

20. Gawryszuk A, Bijl HP, Holwerda M, et al.: Functional swallowing units (FSUs) as organs-at-risk for radiotherapy. Part 2: advanced delineation guidelines for FSUs. Radiother Oncol. 2019, 130:68-74. 10.1016/j.radonc.2018.09.022

21. Gawryszuk A, Bijl HP, Holwerda M, et al.: Functional swallowing units (FSUs) as organs-at-risk for radiotherapy. Part 1: physiology and anatomy. Radiother Oncol. 2019, 130:62-67. 10.1016/j.radonc.2018.10.028

22. Petkar I, Rooney K, Roe JW, et al.: DARS: A phase III randomised multicentre study of dysphagia-optimised intensity-modulated radiotherapy (Do-IMRT) versus standard intensity-modulated radiotherapy (S-IMRT) in head and neck cancer. BMC Cancer. 2016, 16:770. Accessed: April 14, 2020: 10.1186/s12885-016-2813-0

23. Carnaby-Mann G, Crary MA, Schmalfuss I, Amdur R: “Pharyngocise”: randomized controlled trial of preventative exercises to maintain muscle structure and swallowing function during head-and-neck chemoradiotherapy. Int J Radiat Oncol Biol Phys. 2012, 83:210-219. 10.1016/j.ijrobp.2011.06.1954

24. Paleri V, Roe JWG, Strojan P, et al.: Strategies to reduce long-term postchemoradiation dysphagia in patients with head and neck cancer: an evidence-based review. Head Neck. 2014, 36:431-443. 10.1002/hed.23251

25. van der Molen L, van Rossum MA, Burkhead LM, Smeele LE, Rasch CR, Hilgers FJ: A randomized preventive rehabilitation trial in advanced head and neck cancer patients treated with chemoradiotherapy: feasibility, compliance, and short-term effects. Dysphagia. 2011, 26:155-170. 10.1007/s00455-010-9288-y

26. Kotz T, Federman AD, Kao J, et al.: Prophylactic swallowing exercises in patients with head and neck cancer undergoing chemoradiation: a randomized trial. Arch Otolaryngol Head Neck Surg. 2012, 138:376-382. 10.1001/archoto.2012.187

27. Chen AM, Li BQ, Lau DH, et al.: Evaluating the role of prophylactic gastrostomy tube placement prior to definitive chemoradiotherapy for head and neck cancer. Int J Radiat Oncol Biol Phys. 2010, 78:1026-1032. 10.1016/j.ijrobp.2009.09.036

28. Bauml JM, Vinnakota R, Anna Park Y-H, et al.: Cisplatin every 3 weeks versus weekly with definitive concurrent radiotherapy for squamous cell carcinoma of the head and neck. J Natl Cancer Inst. 2018, 133133. 10.1093/jnci/djy133

29. Sedghizadeh PP, Billington WD, Paxton D, Ebeed R, Mahabady S, Clark GT, Enciso R: Is p16-positive oropharyngeal squamous cell carcinoma associated with favorable prognosis? A systematic review and meta-analysis. Oral Oncol. 2016, 54:15-27. 10.1016/j.oraloncology.2016.01.002

30. Adelstein DJ, Li Y, Adams GL, et al.: An intergroup phase III comparison of standard radiation therapy and two schedules of concurrent chemoradiotherapy in patients with unresectable squamous cell head and neck cancer. J Clin Oncol. 2003, 21:92-98. 10.1200/jco.2003.01.008 